\title{
Simulation Modeling of Aerial Work Completed by Helicopters in the Construction Industry Focused on Weather Conditions
}

\author{
Andrej Bisták ${ }^{1, * \mathbb{D}}$, Zdenka Hulínová $^{1}$, Michal Neštiak ${ }^{2}$ and Barbara Chamulová ${ }^{1}$ \\ 1 Department of Building Technology, Faculty of Civil Engineering, Slovak University of Technology in \\ Bratislava, 81005 Bratislava, Slovakia; zdenka.hulinova@stuba.sk (Z.H.); barbara.chamulova@stuba.sk (B.C.) \\ 2 Department of Numerical Forecasting Models and Methods, Slovak Hydrometeorological Institute, \\ 83315 Bratislava, Slovakia; michal.nestiak@shmu.sk \\ * Correspondence: andrej.bistak@stuba.sk
}

Citation: Bisták, A.; Hulínová, Z.; Neštiak, M.; Chamulová, B. Simulation Modeling of Aerial Work Completed by Helicopters in the Construction Industry Focused on Weather Conditions. Sustainability 2021, 13, 13671. https://doi.org/ $10.3390 /$ su132413671

Academic Editor: Antonio Caggiano

Received: 18 November 2021

Accepted: 8 December 2021

Published: 10 December 2021

Publisher's Note: MDPI stays neutral with regard to jurisdictional claims in published maps and institutional affiliations.

Copyright: (c) 2021 by the authors. Licensee MDPI, Basel, Switzerland. This article is an open access article distributed under the terms and conditions of the Creative Commons Attribution (CC BY) license (https:/ / creativecommons.org/licenses/by/ $4.0 /)$.
Abstract: The aim of this research was to develop a simulation model of the works carried out by helicopters, which are used in the construction of buildings under harsh natural conditions. This work identified that even technologies that we do not normally encounter, such as aerial work using helicopters, can have a major impact on ensuring the requirement of sustainability within the overall environmental and economic context. In the environment of protected landscape areas and national parks, in particular, where all sites are sensitive to human intervention, the use of helicopters in construction functions is an irreplaceable aid. Preparations for aerial work are very demanding and require the use of more sophisticated tools to achieve optimal results consistent within the paradigm of long-term sustainability. Simulation modeling is one such option, thanks to the considerable advancements made in information technology. A simulation model of aerial work was compiled within the presented work, and its functionality was verified using specific examples that confirmed in full the suitability of using simulations in the preparation of aerial work within construction. A detailed analysis of helicopter operations showed that an algorithm that accounts for future weather conditions at the construction site, and specifically focused on the conditions at the given altitude above the ground, should be a dominant feature of simulation models. It is exceptionally important that such data be known within the preparations for aerial work as accurately as possible, and, as such, this article describes the process of obtaining meteorological information for simulation models in detail using a numerical weather forecast and the reliability of data obtained in this manner. Based on the results obtained during this research, the proposed simulation model can be recommended as a suitable tool in the preparation of buildings. Its use is especially important if construction takes place under difficult natural conditions, where work cannot be carried out without the use of helicopters. We perceive the simulation model as a potential tool for digitizing construction preparations in the age of Industry 4.0 .

Keywords: sustainable construction; digital technology; helicopter; simulation model; numerical weather prediction; project performance

\section{Introduction}

Aerial work with helicopters has been conducted in the construction industry for many decades. Its introduction into practice resulted from the successful development of a previously unknown type of aircraft with rotating wings-the helicopter. Serial production of the first type of helicopter began during World War II, in 1942. This historic milestone was the start of a qualitatively different stage in the development of helicopters, which were no longer just an experiment, but at that time a perfect serial aircraft that allowed for various uses in military and civilian spheres [1]. In Slovakia, or in the territory of the former Czechoslovakia, aerial work using helicopters in the construction industry began in 1957 [2] (Figure 1). Despite its relatively long history, the technology of aerial work using helicopters has not been surpassed in many respects to the present. 


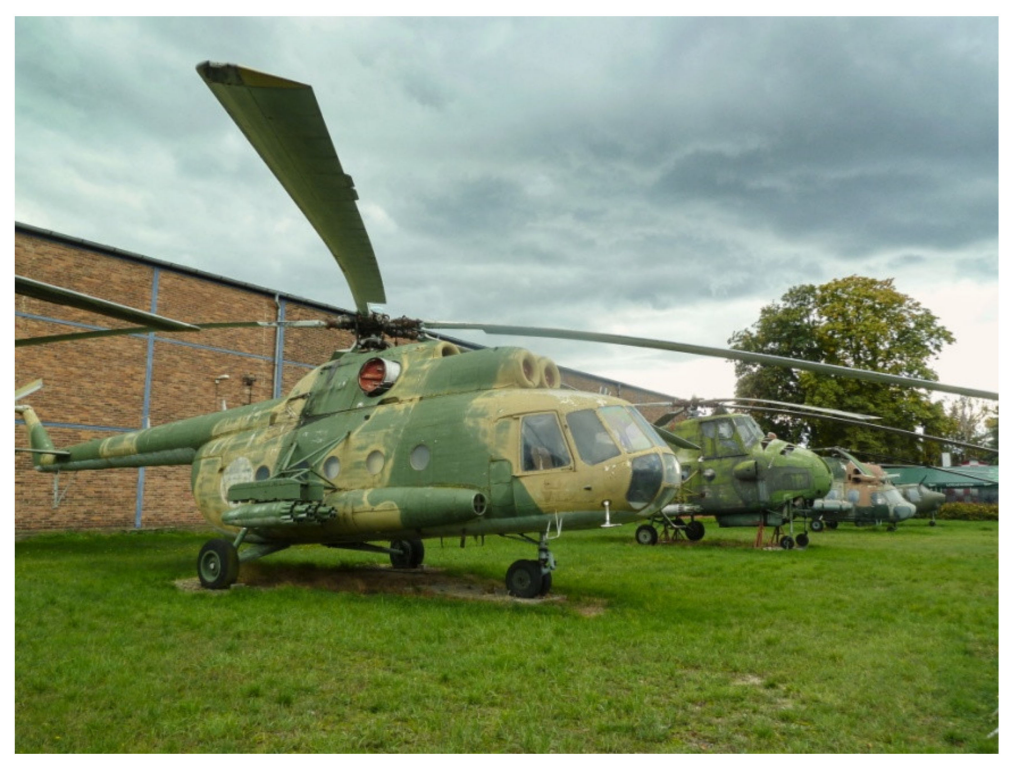

Figure 1. Types of helicopters used in aerial work in the former Czechoslovakia, exhibited at the Aviation Museum of Prague-Kbely (Czech Republic). The Mi-8 type is in the foreground, and its predecessor, the Mi-4 type, is behind it.

Nowadays, sustainability is becoming a fundamental requirement in almost every field of human activity, and helicopter aerial technology-based work is invaluable in sustainability terms, especially in an environmental context. Its extremely specific character provides diverse possibilities for use, mainly outside built-up areas and especially in mountainous areas, which comprise a substantial part of the territory of Slovakia. In mountainous locations, there are often legally protected areas, such as national parks, protected landscapes, or nature reserves, particularly vulnerable to any human intervention [3]. However, such areas are sometimes found outside mountain units, in flat landscapes. Unlike the conventional, ground-based construction method, the land and ecosystem are not disturbed during such aerial work $[4,5]$, meaning there is no need to establish or extend access roads $[6,7]$. In addition to the inevitable accompanying construction traffic, these may also contribute to the deforestation of the landscape with their possible concomitant consequences. There is no need for the establishment of material stockpiles or other components of site equipment (these will only be constructed at a location when it is advantageous and permissible), and there is no need for significant ground disturbance.

Aerial work in which helicopters are used is also proving its benefits in areas with less or no nature protection, such as the densely built-up inner zones of large cities. They are also used in the reconstruction of existing buildings [8]. As a result of the above side effects, construction work carried out by helicopters can be cheaper than it would be with conventional ground technology, and its time duration can be shorter. Therefore, we can also talk about economic sustainability—characteristic for aerial work that it is carried out in a three-dimensional space (the atmosphere), which is strongly influenced by the current weather conditions primarily [9]. Thus, the very nature of aerial work naturally implies that its preparation is more demanding compared to that of conventional technologies [8]. Therefore, it is necessary to choose such means and methods that will help to ensure (to some extent) not only the obvious environmental sustainability, but also the real economic and practical benefits of this technology, and thus, ultimately, the legitimacy of its existence and the long-term sustainability of this method of construction.

The concept of this article is based on the following assumptions: (1) Helicopters are a suitable alternative for work under difficult natural conditions in terms of environmental and economic sustainability, (2) the use of helicopters is significantly affected by weather conditions, and (3) the preparation of aerial work using helicopters is demanding and requires the use of more complex tools, such as simulation modeling. 
Helicopters are used in the construction industry in many countries, but it is a very demanding technology. Its use depends on several factors associated with the design of the helicopter itself, its mode of movement, and the specific, especially weather, conditions in which it can operate.

In Slovakia, the use of helicopters is currently diverse. For example, in 2011-2012, construction of the connection between the northern and southern sides of Chopok Peak in the Low Tatras by cableways commenced. This demanding construction project posed a logistical challenge, and helicopters played a significant role in its successful implementation. Helicopters were used in the concrete and assembly processes on the difficult-to-access construction site, situated on both sides of the mountain ridge and just below the summit of Chopok at an altitude of $2003 \mathrm{~m}$ above sea level.

Helicopters are also used in the Czech Republic, where, for example, from 2011 to 2014 a new cableway was built to the highest Czech mountain, Sněžka (1603 m above sea level) [10]. The construction site was, for the most part, located in the first zone of the Krkonoše National Park. It is an area of arctic-alpine tundra, which is very sensitive to any human activities. Construction work in this area cannot be carried out using conventional heavy construction equipment, so the use of helicopters was an acceptable solution.

Around the world, the work of helicopters in construction is handled by several specialized companies that use various types of helicopters from renowned manufacturers. One of the best-known companies is the Swiss company Heliswiss International AG, which operates mainly in the Alpine countries and in Western Europe. The company operates Kamov KA 32 and AS 332 helicopters.

Helicopters have been used in the United States of America (USA) in the construction of many electrical transmission lines. Helicopters allow construction work to be completed in terrain, where the deployment of conventional equipment is problematic for technical and environmental reasons. Construction of the "Susquehanna to Roseland Electric Reliability Project" is one of many such projects. The objective of the project was to construct a $500 \mathrm{kV}$ transmission line from Pennsylvania to New Jersey [6]. The projected route of the power line crossed a freshwater wetland at the Troy Meadows site, which is protected by the U.S. Environmental Protection Agency. In this $12.5 \mathrm{~km}^{2}$ area, seven poles of the original $230 \mathrm{kV}$ line were located and needed to be replaced with new poles for the proposed $500 \mathrm{kV}$ line.

Helicopter construction technology eliminated the risks associated with the construction and maintenance of access roads with a minimum area of $10,000 \mathrm{~m}^{2}$ and paved work areas with an additional area of $11,000 \mathrm{~m}^{2}$, which also posed a threat to protected plant and animal species. Thanks to the technology used, the implementation of the project was carried out with minimal impact on the surrounding environment of the Troy Meadows Conservation Area [6].

In some situations, the responsible authorities may even prohibit the use of groundbased technology altogether, as was the case with the construction of the $161 \mathrm{kV}$ "Jack Rabbit-Big Sky" power transmission line. The terrain conditions, especially the environmental protection measures, again did not allow the construction of access roads, so most of the construction work (installation of masts, including equipment, backfilling, stretching, and installation of wires) was carried out by helicopters [7].

The extensive portfolio of helicopter constructions of this type in the USA has been complemented by the " $230 \mathrm{kV}$ Northern Intertie Transmission Line" project, which dealt with the construction of a $154 \mathrm{~km}$-long electric transmission line running through the subarctic zone of Alaska [11]. It has also been complemented by the replacement of two damaged poles of the $138 \mathrm{kV}$ "Koolau-Pukele" line in Hawaii, under the extreme terrain and weather conditions of the mountain ridge [12]. Helicopters also find application in diametrically different areas of construction; for example, in the project to replace the suspension cables on the Luling Bridge (Luling, LA, USA), they enabled elegant elimination of inappropriate loading of the bridge deck by heavy truck cranes [13]. 
Thorough construction-technological preparation is required for aerial work using helicopters because during the construction preparation stage, it is still possible to significantly influence the overall concept and organization of the construction of such projects. Due to the complexity of aerial work using helicopters, which are subject to a number of random influences (especially variable weather conditions), it is necessary to use more complex tools during preparation, such as simulation modeling. This can perfectly prepare the course of helicopter work even under difficult construction conditions, while taking into account technical, technological, economic, and environmental aspects.

The influence of weather conditions on construction is of interest to many authors. To assess the severity of this impact, several authors have successfully used a simulation approach (such as Lee et al. [14] and Jung et al. [15]). The authors AbouRizk and Wales [16], who investigated the influence of weather on the completion of earthworks using neural networks, also dealt with considerations for weather conditions in the planning of the construction process. Their research took into account the influence of three meteorological elements: precipitation activity and the maximum and minimum daily air temperatures. The authors did not deal with the influence of other factors or with the possible change in their influences due to changing seasons. Muhabie et al. [17] investigated the simulation of the process of constructing unconventional structures, such as offshore wind farms, which, in addition to weather conditions, also simulated the sea level.

Based on an analysis of the impact of weather conditions on labor productivity, Lee et al. [14] stated that weather conditions have a significant impact on labor productivity, with some meteorological elements having a greater impact than others. Jung et al. [15] described a simulation model based on a future weather generator at the construction site of high-rise buildings. The basis of the simulation model is a weather generator, on the basis of which the expected construction delay relative to the impact of adverse weather conditions can be determined and incorporated into the construction schedule.

Weather generators are based on the values of meteorological elements, measured at ground level. However, according to the authors, this can be a problem in the construction of high-rise buildings because weather conditions change with increasing height; changing conditions may therefore affect the course of construction of the upper floors of a highrise building. To solve this problem, the authors proposed a simulation model that took into account the correlation between altitude and weather conditions. The proposed model was verified on a 50-story office building. The simulation results pointed out several facts, namely: that without taking into account the influence of altitude, there are significant differences in estimating the degree of dependence of the construction process on weather conditions; that observed differences increase with the height of the structure; that time series of meteorological elements, especially wind speeds, do not appear in the one-year seasonal component; that seasonality is natural for the values of meteorological elements [15].

The main element of such simulation models is a weather generator. This is classified among the numerical models, "artificially" creating the values of individual meteorological elements on a daily basis. These data have the same probability distribution as the historical weather data entered into the generator [18]. Generators are used in the creation of simulation models in various areas of industries, e.g., in agriculture, ecology, and in the generation of electricity in wind power plants [19]. A statistical set of historical data on weather conditions in the area is entered into the generator. Based on such, using probability theory and mathematical statistics, the generator simulates the values of individual meteorological elements such as precipitation, temperature and relative humidity, and wind speed. These are variables that ultimately affect labor productivity and costs, and they may even interrupt work [20].

The simulation of future weather conditions at the construction site, carried out on the basis of historical data, is associated with a certain degree of inaccuracy. According to Kim and Augenbroe [21], these computational models do not adequately capture the randomness and uncertainty associated with weather forecasting. Other differences may 
also occur in connection with gradual climate change [22]. Our research shows that it is possible to increase the accuracy of the data entering the simulation model and, thus, increase the rate of approximation to the actual conditions at the construction site by using one of the commercially available numerical weather forecasting models. These models provide the necessary short-term forecast (e.g., [23]). We applied this approach in our next solution (Section 2.3).

Partial conclusion: According to the analysis, research in the field of simulation modeling in the preparation of buildings is only in its infancy, and several authors have emphasized the need to publish other works using the simulation approach. In their works, many of them have already dealt with simulating future weather conditions and evaluating their impact on the construction process, but only conventional processes have been simulated, especially using conventional cranes and other common construction equipment.

Helicopters have long been used in various areas of construction and today are a tool without which construction work would not be possible to complete efficiently, or at all in some cases. They are applied to a broad spectrum of activities in mountain and developed areas. In Slovakia, however, the preparation of aerial work is still carried out in a traditional way. The key parameter, which is the helicopter payload capacity, is determined manually by means of its load capacity nomogram in paper form (Section 2.2).

In the case of designing a construction process to be performed by a helicopter, the effectiveness of the final solution becomes the key criterion. Due to the specifics of these aerial works and their susceptibility to many factors, it is more difficult to predict their actual course using traditional deterministic models. Any resulting inaccuracy in time and cost planning will then negatively affect the entire construction process. A suitable tool for determining the optimal variant is simulation modeling, which adequately represents the authenticity of variable conditions in real-world construction practice. Balakchina and Shalenny [8], in their work, pointed out the need to verify various variants of technological procedures in aerial work using simulation modeling.

The elaboration of such a topic will make it possible to verify the potential applications of the simulation approach in another little-explored area of the construction industry, which will ultimately contribute to the wider application of progressive simulation modeling tools in construction practice. It will also create a framework for developing institutional education in simulation. It is these areas that several contemporary authors have described as being the most problematic.

The results of such a solution could be usable in the future outside the construction industry, especially in logistics. Applied knowledge from the use of various numerical weather forecasting models can also be beneficial for the field of numerical meteorology. The idea of an interdisciplinary approach is in line with the recommendations of various authors around the world, including, for example, Lee et al. [24].

\section{Methods}

Due to their characteristics, helicopters represent a practical and indispensable means of transport for many industries. The ability to take off and land perpendicularly without relying on long runways grants helicopters an unusually broad operating space, as they do not require a large or specially prepared area to land and take off. Unconventional maneuvering capabilities allow helicopters to perform flights in close proximity to the ground. The lower transport speed of helicopters compared to other aerial vehicles is an advantage when transporting loads [25]. Helicopters are able to fly in all directions, and, unlike conventional aircraft, they can also be stopped mid-air by hovering. It is the combination of these characteristics that has also enabled the use of helicopters in the construction industry [2].

\subsection{Aerial Work in Terms of Helicopter Performance}

During each phase of flight, the helicopter must meet specified performance parameters, particularly the ability to hover at the take-off point, the ability to maintain a specified 
rate of climbing on specified sections of the flight, and the ability to land at a specified location-all in such a way that fixed objects (obstacles) are safely negotiated [26]. The performance of a helicopter is influenced by its design and the engine(s) used, which is a given in its design and manufacture. The practically achievable performance of the helicopter is further influenced by the atmospheric conditions in the specified location, as well as its actual weight and configuration. The performance of a given helicopter, including the effect of atmospheric conditions and its weight and configuration, is always specified in aviation practice in the so-called flight manual of the particular helicopter.

The original definitions for helicopter performance were derived from the performance definitions for conventional aircraft. However, unlike these aircraft, helicopters do not take off and land only on runways, but rather they use helipads or areas of different characteristics with various surrounding obstacles. Compared to conventional aircraft, helicopters have the capability of vertical climbing or rear or lateral guidance during take-off and partially during landing. This capability of helicopters is possible, according to [26], for use in the application of different take-off and landing procedures. However, all procedures must comply with the safety requirements and eliminate danger to persons on board and on the ground. This means that the time during which the helicopter is unable to make a safe forced landing in the event of a power unit failure must be minimized. The use of a certain procedure minimizes this time only for a certain type of heliport (area) and its surroundings. Another reason for differentiating procedures is the different performances among helicopters. A procedure that is most advantageous for a helicopter of a particular size may not be applicable to a helicopter of a different performance class. Therefore, different procedures are defined not only according to the type of landing area (helipad, elevated helipad, helideck, etc.), but also according to the performance classes of helicopters [26].

Helicopter performance is therefore primarily influenced by the following factors [26,27]: pressure altitude and density altitude, humidity, air temperature, wind, the weight of the helicopter, the helicopter configuration, and the position of the helicopter's center of gravity.

Weather conditions affect the entire construction process and not just helicopter work [22]. Chief among them are temperature and wind, as well as rain, snow, and storms. However, aerial work using helicopters is carried out at higher altitudes than the ground at which normal construction takes place, where these conditions are significantly more intense, which significantly affects the performance of the helicopters themselves and their ability to be used for construction work.

\subsection{Aerial Work from the Technological-Organizational Point of View}

For aerial work using helicopters, there are, according to Dosoudil et al. [28], two basic methods of transporting loads: transport in the helicopter's fuselage compartment (used for transporting people and smaller loads, where the loading and unloading points must allow the helicopter to land) and transport via the helicopter's undercarriage (used when it is not possible to land the helicopter at the loading and unloading points). However, the primary reason for the use of helicopters in the construction industry is the existence of the latter option, which is used in practice in the implementation of most construction processes by this technology.

The Mi-8 helicopter, frequently used in Slovakia, has a maximum load weight of $4000 \mathrm{~kg}$ in the fuselage and $3000 \mathrm{~kg}$ in the undercarriage, with external suspension lengths of 5-50 m. The length of the suspension is determined by the helicopter crew, mainly according to the height of surrounding obstacles and the longitudinal slope of the terrain. The material is transported according to its type and quantity on pallets, in containers, in bundles, or individually [28]. According to these authors, helicopter transport flights consist of three basic phases: (1) suspension of the load and departure of the helicopter with the load as the airspeed increasing to cruising speed, (2) movement of the helicopter at cruising speed along the transport route (the speed cannot be influenced because it is 
given for the specific type of helicopter), and (3) slowing the helicopter to zero speed and emptying/disconnecting the load.

From the above, it is clear that the duration of one flight cycle can be influenced in the first and third phases (guiding the load into the unloading area and disconnecting and suspending the load). Before the actual implementation of aerial work, it is necessary to find a suitable type of helicopter because the only influence that technologically limits the use of helicopters is its carrying capacity. This is different for each type and is determined by the power of the propulsion units and other technical parameters of the helicopter. With lifting capacity acting as a limiting factor, the maximum weight of an individual load is sometimes critical in determining the appropriate type of helicopter [28]. However, helicopters can practically be used for construction work only, provided that the weights of the transported structures do not exceed the permissible weight of the load for the given altitude of the installation site and the atmospheric conditions of the environment. Weather conditions significantly affect the parameters of a helicopter, especially the most technologically important value, i.e., the lifting weight (lifting capacity).

When using a helicopter for aerial work in the construction industry, various specific organizational conditions must also be met, which have been summarized by Bartoš et al. [29]. The authors stated that each load must be weighed, and the weight of the load must correspond to the helicopter's load capacity nomogram. The mounting altitude is given (limited) in terms of the helicopter's lifting capacity nomogram in relation to the weight of the suspended load. The place for suspending the load and the place of its mounting must be vertically free, with dimensions of a minimum of $40 \times 40 \mathrm{~m}$ and up to a height of $30 \mathrm{~m}$ above the installation site. For complicated assemblies, modifications must be made at the place of assembly or directly on the load to simplify the guiding and fitting of the load. The installation of high-rise buildings at heights above $25 \mathrm{~m}$ above the surrounding terrain requires the installation of auxiliary guidance equipment. The speed of the descending airflow from the helicopter rotor blades onto the ground reaches $22-25 \mathrm{~m} / \mathrm{s}$, which, especially in closed industrial buildings, leads to a high amount of dustiness and the floating of light objects, so these objects must be secured and surfaces must be cleaned. In the case of the block construction of steel structures, towers, chimneys, masts, etc., it is necessary to maintain its slenderness with a maximum value of 1:9 with regard to the stability of the load because exceeding the slenderness limit leads to a disturbance of the load's stability due to the movement of the helicopter.

After many time measurements of the assembly of excessively lean loads, Bartoš et al. [29] stated that the time value of setting a load with a leanness of 1:10-1:12 is more than double, sometimes even triple, when compared to setting a load with a slenderness of up to 1:7. Based on this experience, the authors recommended that this knowledge be taken into account when designing new steel structures to be fabricated by helicopter. These authors also addressed the content of the optimal technological procedure for aerial work in construction, which should include the determination of the helicopter's position and its fuel quantity, the design of suitable transport packages and containers for loads, the method of connecting and fastening loads, the identification of loading points, the marking of dump sites, the method of returning empty transport packages, the most advantageous number of flight cycles per helicopter take-off, the identification of the shortest overflight routes, and a reliable solution for communication between the different locations of the planned aerial work (e.g., the use of radios). In terms of the one preparing the construction, the division of individual types of activities in the implementation of aerial works is also extremely important, on which Bartoš et al. [29] wrote in their work. Flight activity is the actual execution of the working flight, or overflight, and its preparation in accordance with the related aviation regulations (planning of the flight activity, assessment of the specific conditions of the working flight in terms of the current meteorological situation, and coordination with the assembly group) and reconnaissance of the terrain. Technical activity ensures the technical capability of the helicopter in accordance with the relevant aviation safety rules and technical regulations (technical flight preparation, possibly necessary maintenance of aviation equipment, operation 
of and maintenance of suspension equipment, etc.). Auxiliary activity supplies the helicopter itself with aviation fuel, moving personnel, and material on the ground, and it ensures mutual communication. Assembly activity involves placement of the load on the terrain and its assembly security, preparation of loads for fastening under the helicopter, and the fastening itself. Organizational activity involves controlling the compliance with all conditions for the successful execution of the entire contract and individual works, contractual conditions, and safety regulations imposed by the customer or the cooperating assembly organization.

As a rule, flight, technical, support, and organizational activities are carried out by the staff of the aeronautical operator. The helicopter is to be supplied with aviation fuel during operation and equipped with launchers, miscellaneous material, operational flight planning capability, and crew, as well as personnel mobility capability on the ground. The autonomy of a helicopter is adversely affected by its basic characteristics alone, e.g., a short range at full load, as a result of which the amount of refueling before a working flight is limited for weight reasons. When analyzing helicopter work, it is significant that, unlike other activities in aviation, each construction and each helicopter working flight represents a unique event that must be dealt with both in preparation and in execution comprehensively with the participation of all of the aforementioned components. Moreover, this complexity is concentrated in one common time period, and the different activities overlap one other in the development of a joint project. Thus, every construction and work flight require a comprehensive engineering solution to all problems in a coordinated manner by all the above-mentioned components [29].

Before carrying out aerial work, those preparing the site must search for a suitable type of helicopter because the ultimate influence that limits the practical use of helicopters is its carrying capacity. The payload capacity is different for each type of helicopter and is determined at the time of design and manufacture. However, a helicopter with a specific maximum load capacity can only be used provided that the weight of the load does not exceed its permissible value, related to the specific construction site, i.e., its altitude and weather conditions. Weather conditions significantly affect a helicopter's payload capacity, which is the most critical in terms of construction technology. Unlike conventional lifting equipment, the maximum lifting capacity of a helicopter is not constant, but it varies over time. For this reason, the preparatory phase of aerial work must necessarily take into account the course of weather conditions on the future construction site at the time of implementation. In practice, only some of the described meteorological elements have a significant influence on the determination of the helicopter's actual payload capacity, so we can mathematically express the abovementioned dependence for a known location of helicopter use as follows:

$$
C=f\left(t, a, p, w_{s}, w_{d}, v\right)
$$

where $C$ is the lifting capacity or maximum take-off weight of the helicopter, $t$ is the air temperature, $a$ is the altitude, $p$ is the air pressure, $w_{s}$ is the wind speed, $w_{d}$ is the wind direction, and $v$ is the visibility. In aviation practice, the relationship between air temperature, altitude, wind speed, and maximum take-off weight of the helicopter is represented by a nomogram. The nomogram is valid for a specific type of helicopter and is part of its documentation supplied by the manufacturer. The helicopter payload capacity is expressed graphically in the nomogram according to the individual influencing factors. After subtracting the so-called standard load and the fuel weight, which is determined depending on the length of the flight, the actual load capacity of the helicopter can be obtained, i.e., the actual maximum weight of the load to be transported.

\subsection{Numerical Weather Prediction}

Weather conditions are among the main factors affecting the performance of a helicopter and thus its possible deployment, so it is extremely important to know these data as accurately as possible in the preparation of aerial work. In the distant past, the weather factor was taken into account only on the basis of the season. In the territory of Slovakia, the main building season is most often considered to be April to Novem- 
ber; strong frosts are expected in the months of January and February. In professional long-term planning, the previous general statements have been replaced by the statistical treatment of measured meteorological data obtained using the permanent network of meteorological and climatological stations of the national meteorological institutes. In Slovakia, the Slovak Hydrometeorological Institute (SHMÚ), which is a member of the World Meteorological Organization (WMO), is responsible for this activity. Among other activities, the WMO guarantees a uniform methodology for meteorological and climate measurements worldwide.

For long-term planning, it is correct to use the climatic norms for a given location, which are processed in the map outputs. The SHMÚ currently uses two main climate norms, of which the climate norm for the period of 1981-2010 has been fully developed and the climate norm for the period of 1991-2020 is currently being finalized. Basic characteristics include, for example, the monthly mean air temperature, the monthly minimum air temperature, and the monthly mean atmospheric precipitation.

While these values comprise a climatological statistical framework over a given period, numerical atmospheric prediction models are used to predict the actual weather at a given time. According to their computational domain, they are divided into global and local models. Global models cover the entire world and are computed on supercomputers at large meteorological centers such as the ECMWF (European Centre for Medium-Range Weather Forecast) IFS (Integrated Forecasting System), Meteo France-ARPEGE (Action de Recherche Petite Echelle Grande Echelle), and the Environmental Modelling Centre GFS (Global Forecast System). Enormous computing power is required for their operation, which is why these supercomputers are at the top of the TOP500 list of supercomputers [30].

In 2007, Slovakia, and thus also the SHMÚ, became a cooperating country of the ECMWF and gained access to the outputs of the IFS model. The IFS is a 50-member ensemble model that is computed twice a day at 00:00 and 12:00 UTC (Coordinated Universal Time). The maximum forecast length is 15 days, with a resolution of approximately $13.88 \mathrm{~km}$. The basic outputs from the IFS model, labeled as the ECMWF model, are freely available on the SHMÚ website for points of interest within Slovakia with a 10-day outlook. The graphical form of these outputs is the so-called meteogram, which captures the time course of air temperature at $2 \mathrm{~m}$ above the surface, cloud cover, precipitation, air pressure reduced to sea level, and the wind speed and direction at $10 \mathrm{~m}$ above the surface at a selected geographical point. For practical use, it is necessary to select the meteogram for the nearest geographical point to the intended construction site from the menu.

The SHMU has been involved in international cooperation since 1994 [31], participating in the development of the model on the ALADIN boundary area [32]. The main reason and advantage of counting local models is their higher resolution and time availability. At the SHMÚ, the ALADIN (ALARO-1) cy40 system is currently computed with a resolution of $4.5 \mathrm{~km}$ and with the assimilation of local surface measurements, and the domain of which covers Europe (Figure 2). Its boundary conditions are outputs from the global ARPEGE model. The forecast length is three days (Figure $3 a, b$ ).

The aforementioned resolution is essentially a square grid of points over the area of interest, in which the length of the edge of the square corresponds to the magnitude of the resolution of the numerical prediction model. The practical significance of the resolution size is well illustrated by the example of a model representation of the orography of Slovakia. Figure 4a presents a representation of the orography of our territory by the IFS global model (ECMWF) with a resolution of $13.88 \mathrm{~km}$. In contrast to this model, the ALADIN model (SHMÚ) depicts the ruggedness of the terrain of Slovakia more accurately, due to the $4.5 \mathrm{~km}$ resolution used (Figure $4 \mathrm{~b}$ ). 


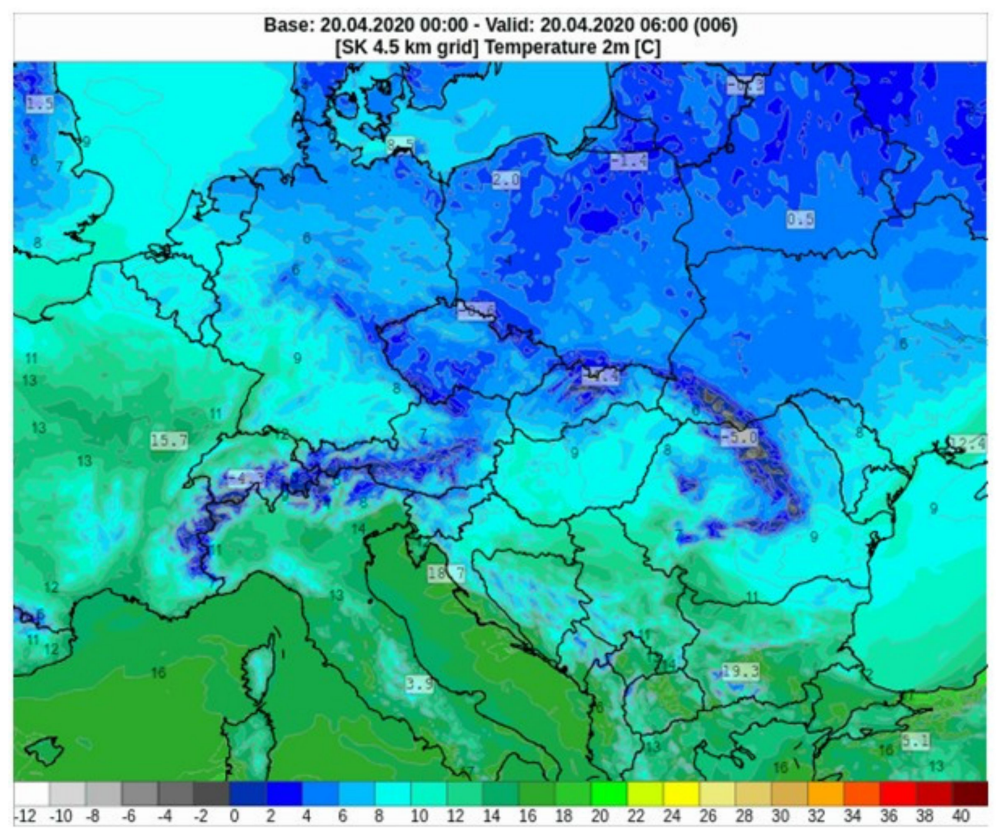

Figure 2. Air temperature field at a height of $2 \mathrm{~m}$ in the Slovak Hydrometeorological Institute (SHMÚ) ALADIN $4.5 \mathrm{~km}$ computational domain.

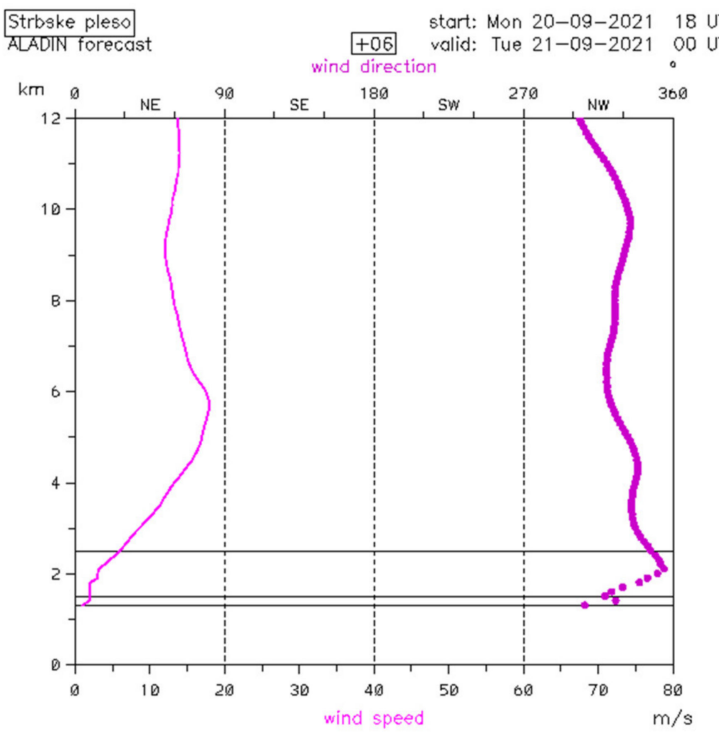

(a)

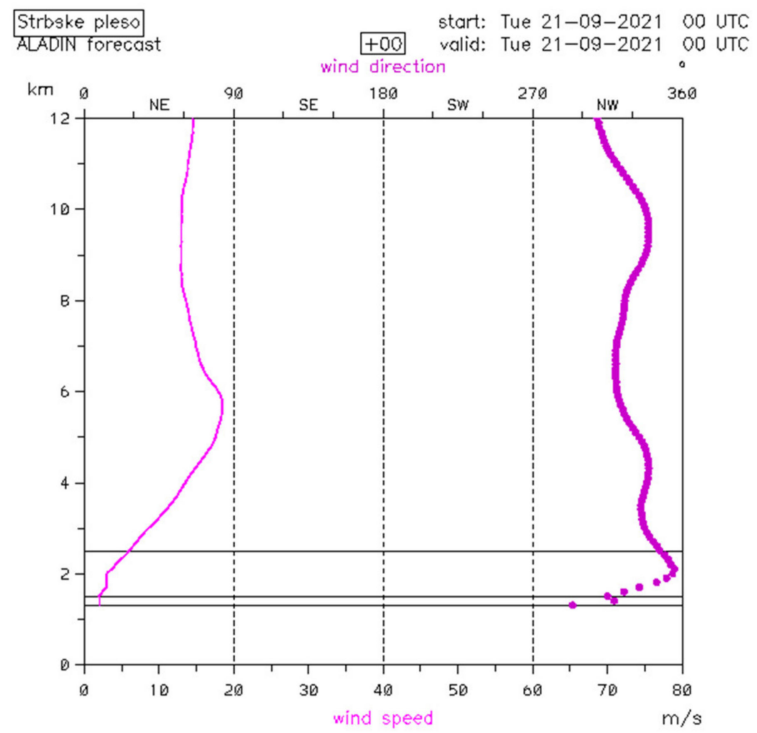

(b)

Figure 3. Wind speed and direction profile calculated by different runs (a,b) of the ALADIN model (SHMÚ ALARO-1) for Štrbské Pleso, Slovakia (1350 m a.s.l.) on 21 September 2021 at 00:00 UTC. 


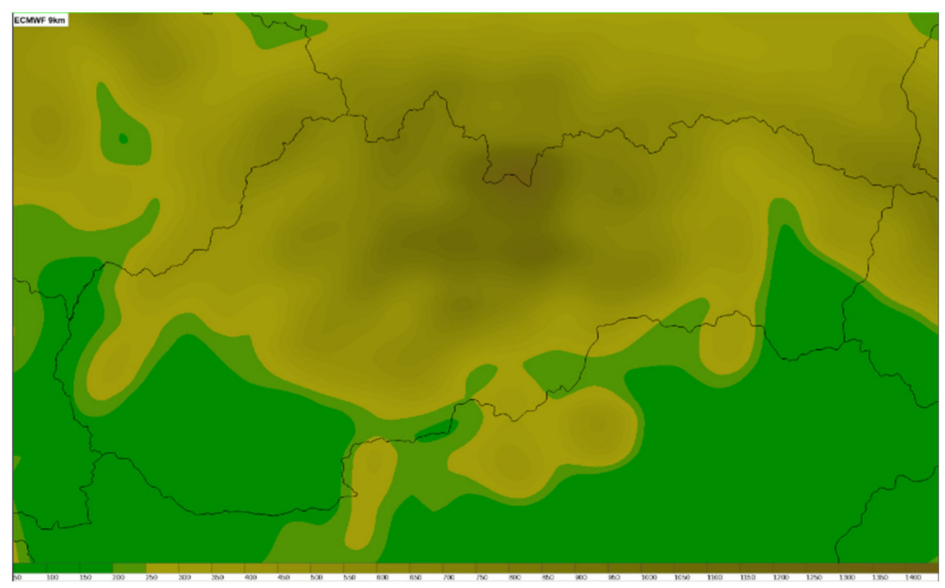

(a)

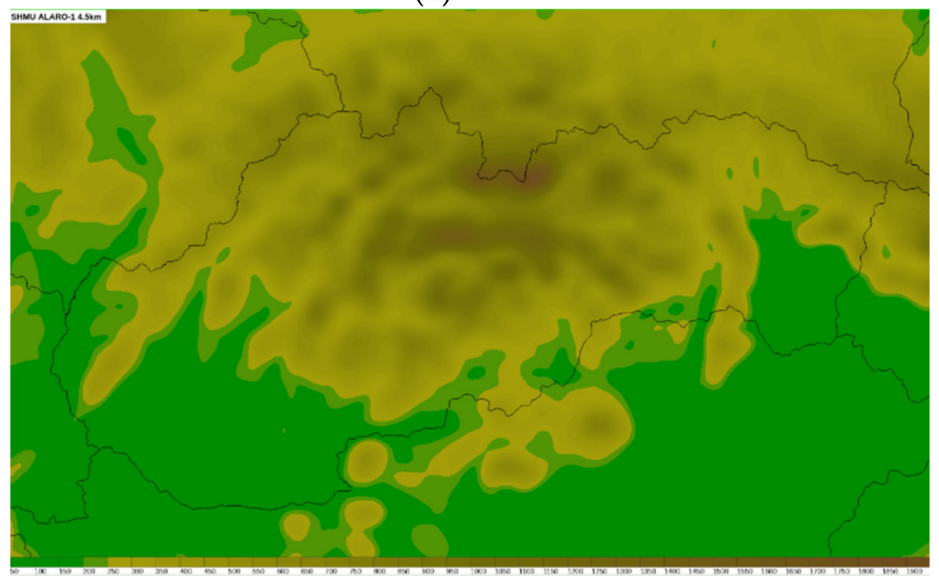

(b)

Figure 4. Comparison of the model orography for the territory of Slovakia on the IFS of the ECMWF (a) and ALADIN of the SHMÚ (b).

The ALARO-1 model, with a resolution of $2 \mathrm{~km}$, is currently being developed and tested, but it only covers the Central European region due to the high computing power requirements. Experiments are also underway with a $333 \mathrm{~m}$ resolution model to determine the effect of resolution on wind speed and gusts. In the future, such models will provide very important information for nowcasting (short-term weather forecasting for 0-6 or $12 \mathrm{~h}$ ahead). The three-hour or up to one-hour computational frequency of such models, instead of the current six hours, is also important. The development of all models is linked to a technical upgrade of the respective high-performance computing technology. In our Central European area, the A-LAEF (ALARO_Limited Area Ensemble Forecasting, Figure 5) ensemble model, which the SHMÚ is working on developing in the framework of RC-LACE (Regional Cooperation for Limited Area Modelling in Central Europe), will play a key role in the three-day planning of construction works [33-35].

\subsection{Simulation Modeling}

The essence of simulation modeling in the construction industry is the creation of a computer model of the construction process as it would take place in reality, followed by subsequent experimentation with the assembled model [36]. The advantages of the simulation approach are particularly evident when processes cannot be described by mathematical relationships and when we want to get as close to reality as possible. The degree of accuracy is determined by the number of simulation runs. 

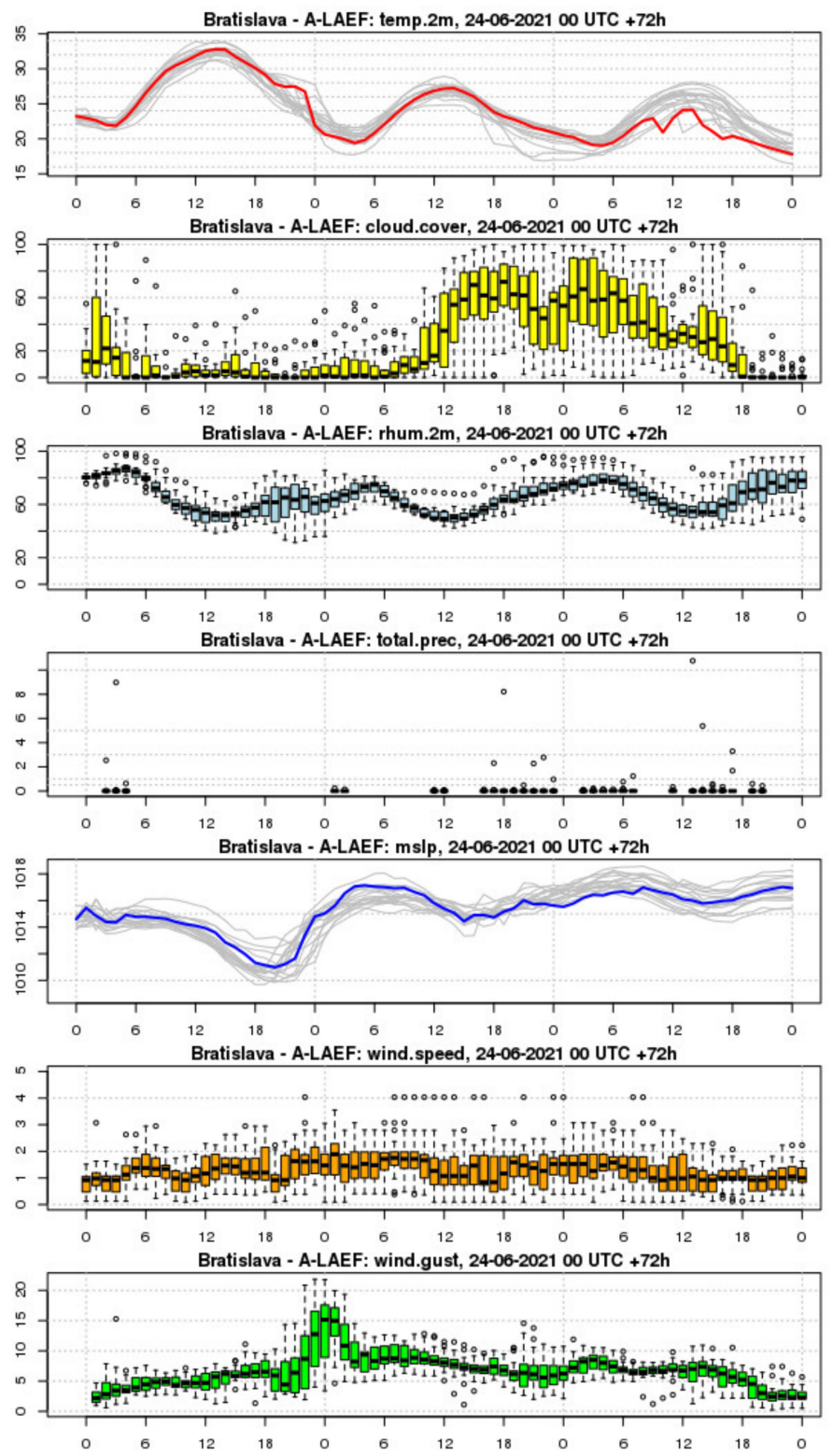

Figure 5. A-LAEF model output for Bratislava (Slovakia) on 24 June 2021 at 00:00 UTC.

Currently, there are a number of simulation programs on the market, from which it is possible to choose the most suitable for creating a model of the construction process under study. The simulation programs used include ExtendSim (formerly Extend), developed in the USA in collaboration with NASA. This program belongs to the group of software dealing with logistics and is designed for the project preparation of production, warehouse management, handling, etc. Its properties thus meet the requirements of its use under the conditions of construction production [37]. Another option is to use the MATLAB programming environment or its simulation superstructure Simulink. MATLAB was also developed in the USA and, thanks to its versatility, can be used in virtually any field of technology.

The construction of a simulation model is preceded by the creation of a simulation scheme. The simulation diagram must represent the construction process as authentically as possible, i.e., as it takes place in reality-it is essentially a graphical (two-dimensional) representation of the algorithm. Once the simulation scheme has been created, the simulation model itself can be designed. A particularly widespread simulation language is CYCLONE, which was proposed by Halpin in 1973. Its output is clear diagrams based on 
six basic symbols [36]. A diagram of the aerial work execution process according to the newer BPMN method [38], which captures a helicopter's sequential steps in transporting loads, is shown in Figure 6.

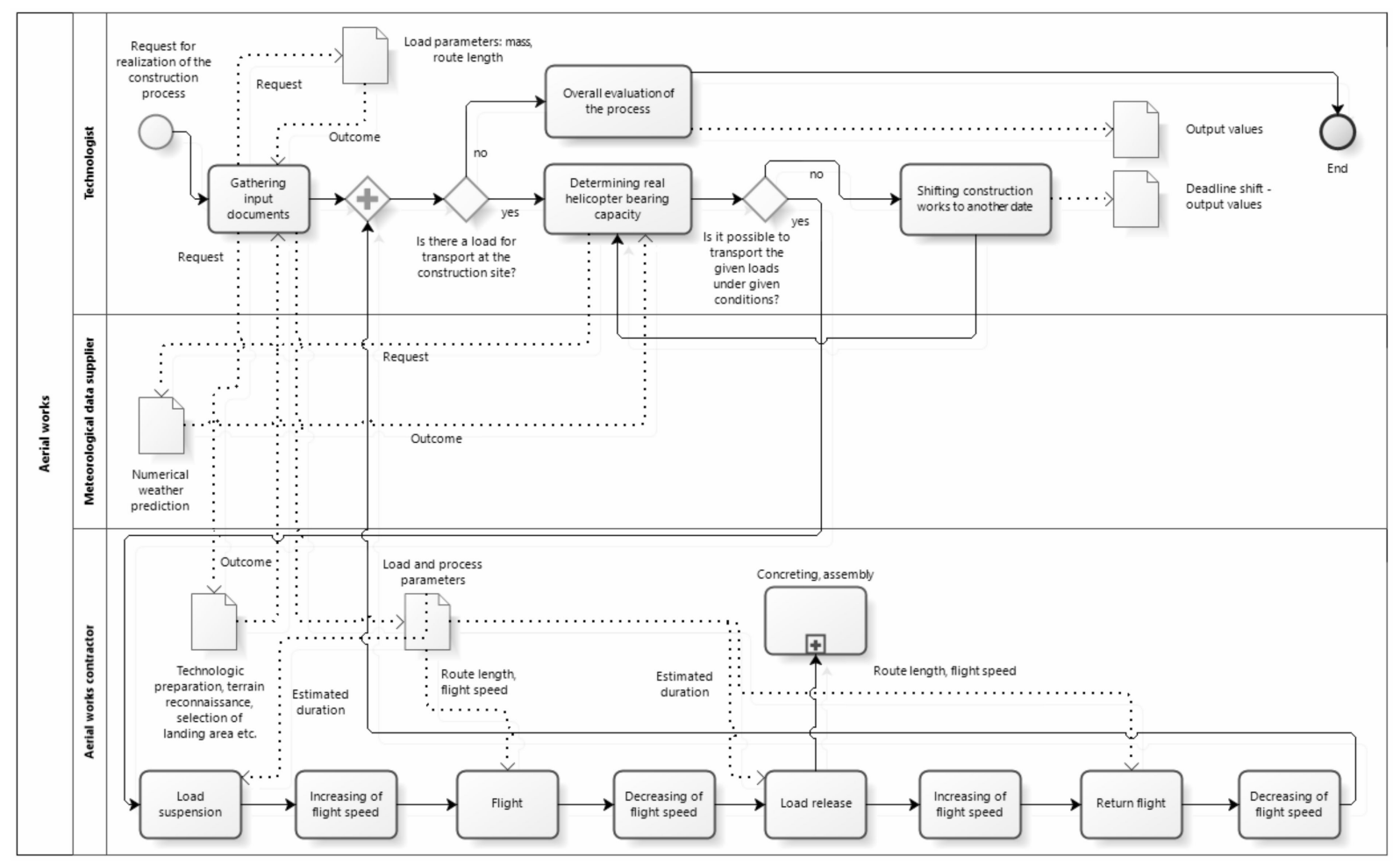

Figure 6. Flowchart of the aerial work execution process using helicopters according to the BPMN method [9].

Simulation modeling can be used in various areas of the construction industry. For example, Mahmoodzadeh and Zare [39] dealt with the probabilistic prediction of the impact of expected geological conditions, construction time, and total cost of the construction of road tunnels. The authors proposed a probabilistic model that predicted the geological conditions at the site of underground structures, and which consequently determined the construction time and cost. The authors presented the proposed model using the example of the construction of the Hamro road tunnel (Iran). A similar issue was addressed by Liu et al. [40], who proposed an adaptive simulation model based on the CYCLONE method and validated it in the example of the construction of a $16.67 \mathrm{~km}$-long tunnel for the Jinping hydropower plant in south-west China. Alsudairi [41] dealt with the possibilities of using the simulation approach in the field of reducing the cost of construction work, shortening the construction time and the maintenance of buildings. Kim, Kim, and Cho [42] used simulation to resolve logistic problems related to the construction of structures made from precast reinforced concrete components.

The influence of weather conditions on construction performance has also been a subject of interest for several authors, but usually on sites constructed using conventional ground technologies. Several authors have successfully used a simulation approach to assess the magnitude of this impact, e.g., Lee et al. [14], Jung et al. [15], and Muhabie et al. [17]. The backbone of such simulation models is a weather generator, which generates predicted values for individual meteorological elements. These data have the same probability distribution as the historical weather data that feeds into the generator [18]. However, the simulation of the future state of weather conditions at the construction site, carried out on the basis of historical data, is associated with a certain degree of inaccuracy. According to Kim and Augenbroe [21], these computational models do not adequately capture the randomness and uncertainty associated with weather forecasting. To increase the level of 
accuracy of the data input into the simulation model, and thus increase the level of approximation to actual site conditions, it is possible to use one of the commercially available numerical weather prediction models (Section 2.3).

In order to help bridge the gap that arose during the preparation of construction due to a large number of random influences affecting the work of helicopters, the MATLAB programming environment was used in the solution of the presented research in order to compile a simulation model of helicopter work. This model was subsequently verified using specific examples in real-life situations.

\section{Results}

As part of the solution of this research task, a simulation program was designed, which was subsequently verified using the examples of the construction of cableway systems in Poland and Slovakia.

When processing the case study that focused on the construction of the $\mathrm{U}$ Kowalskiego-Hala Skrzyczeńska (Szczyrk, Poland) cableway via aerial work technology, the simulation model, due to the nature of aerial works in the construction industry, was based on the principles of discrete simulation. In technical terms, it was a standard mass-produced single-cab cableway pertaining to the circulatory system, with detachable carriers. Due to the fact that most of the input data were discrete in nature, the model was designed directly in the MATLAB environment in the form of a so-called live script, which represents direct writing of the algorithm using MATLAB's own programming language but enriched with interactive controls and interpretation of the algorithm's outputs in real time. This method, due to its illustrative nature and relative simplicity, is also very advantageous from a pedagogical point of view. By choosing this option, it simultaneously responds to the opinion of some authors pointing out the need to include the issue of simulation in university curricula, e.g., [24].

When assessing the severity and overall impact of individual factors on helicopter operation, we also relied on the knowledge and experience of aviation practice. Therefore, factors that show a low or negligible level of significance were not considered in the solution of the simulation model. Due to this reason, the issue of head and tail winds was narrowed down to general wind speeds in accordance with planning procedures in aviation practice and in accordance with the capabilities of the used numerical weather prediction models. A key part of the simulation model is the provision of meteorological input data. This part was designed on the basis of several follow-up steps with successive approximation of the data using different numerical weather prediction models, provided by the SHMÚ.

Relevant numerical weather forecasts are under steady-state conditions within 10 days at most. Therefore, in this section, a two-step procedure was proposed, with the first one being the planning of the implementation of the aerial works at a maximum of 10 days before the requested date. In the second step, from three days before the planned event to its expected date, local models with a higher resolution were used. Thanks to these models, it is possible to confirm the expected nature of the weather and to specify the actual date and duration of implementation. In this interval, it is possible to re-evaluate decisions made every six hours-at 00:00, 06:00, 12:00, and 18:00 UTC, or every one to three hours in the case of rapid update models.

The input data on the loads, their number, and their weight were taken from the weight tables provided to the contractor by the manufacturer of the cableway. The loads were the individual parts of the tubular shafts of the track supports. Information on the length of the transport route for each load was obtained from the longitudinal profile drawing of the cableway route. The transport distance of the load was determined as the so-called developed length between the lower station and the implemented structure (track support). A total of 25 loads were transported in this way. This stage of the research represented the verification of the simulation model, while the simulation results themselves were in line 
with the assumptions and confirmed the logical and factual correctness of the proposed simulation model.

In this step of the solution, the outputs from the ALADIN prediction model were modified in cooperation with the SHMÚ for use in the simulation model in the form of a data file with a defined format. Thus, the discrete data in a computer-processable form for a specific raster point (the construction site) were obtained. The SHMÚ currently generates this data file in the aforementioned interval of every six hours. The interpretation of the new forecast and its impact on the construction work thus only becomes a matter of relaunching the simulation model with the appropriate data file at the input.

In the case of a wider application of the proposed concept, even more advanced automation can be applied as well, and the data file can be downloaded and loaded automatically from the forecast provider. An example of graphically interpreted input data from the ALADIN numerical prediction model for the needs of the simulation model in the Bachledova dolina location (Slovakia) is shown in Figure 7. Figure 7a shows the predicted air temperature over the next $72 \mathrm{~h}$ at various altitude levels of the Earth's atmosphere. Figure $7 \mathrm{~b}$ expresses, by analogy, the predicted course of the wind speed.

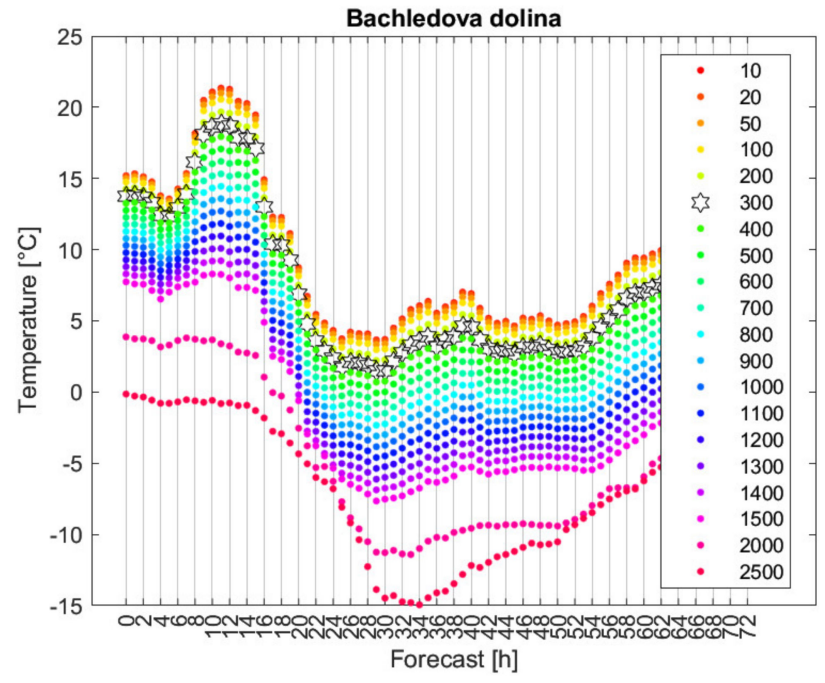

(a)

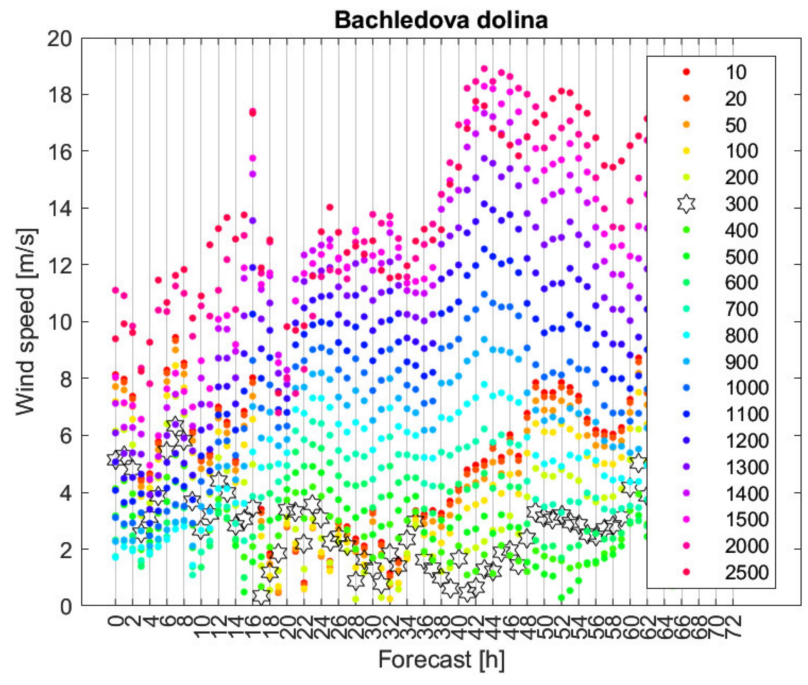

(b)

Figure 7. Interpreted numerical weather forecast for the ALADIN model in the MATLAB programming environment for the Bachledova dolina locality (Slovakia): air temperature (a) and wind speed (b).

The possibilities of practical use of the simulation were then shown in the example of the construction of the Bachledova dolina-Malá Pol'ana cableway (Slovakia). From a technical point of view, it was the same type of cableway as in the previous case. Both facilities are similar in terms of technical parameters-the developed length is $1518.57 \mathrm{~m}$, the elevation of the route is $264.40 \mathrm{~m}$, and there are nine supports along the route. Two variants of the assembly process were assessed, which differed only in the start time of the work. In variant 1 , the start of assembly was planned within $50 \mathrm{~h}$ of the beginning of the validity of the forecast in use; in variant 2 , this period was $10 \mathrm{~h}$ of the beginning of its validity, which corresponds to a difference of approximately 1.5 days. The resulting values of the individual variants of the aerial work on this construction differed mainly in the duration of unfinished work ( 0 vs. $73.40 \mathrm{~min}$ ), which was caused mainly by changing weather conditions at the construction site (Figure 7a,b) and, thus, the inability of the helicopter to fly in, in certain cases, due to its maximum load capacity at the given time.

We consider the results obtained by the simulation to be credible because they are very close to those that are usually achieved in practice in the case of this type of construction and also fully justify the use of a simulation in the preparation of aerial works in the construction industry. An example of one of the possible graphic outputs of the simulation 
in the form of a histogram of work durations for the two process variants is shown in Figure $8 \mathrm{a}, \mathrm{b}$ and analogously in the form of a box plot in Figure 9a,b.

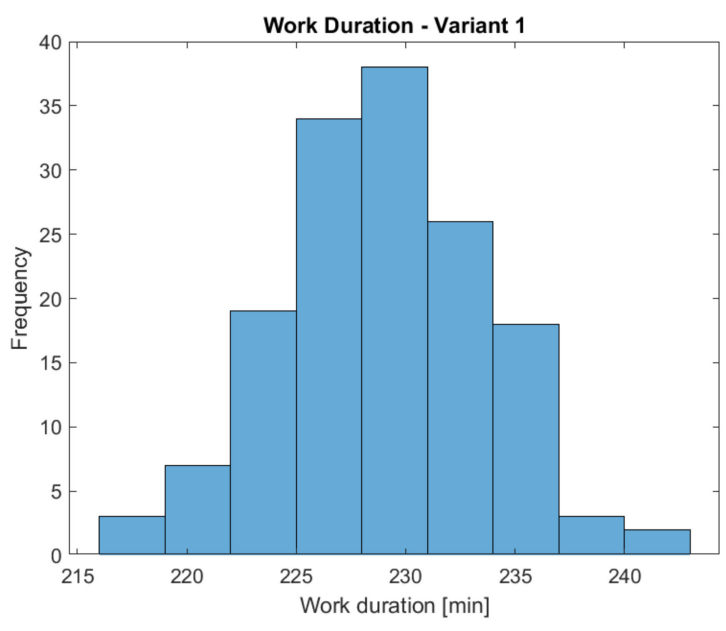

(a)

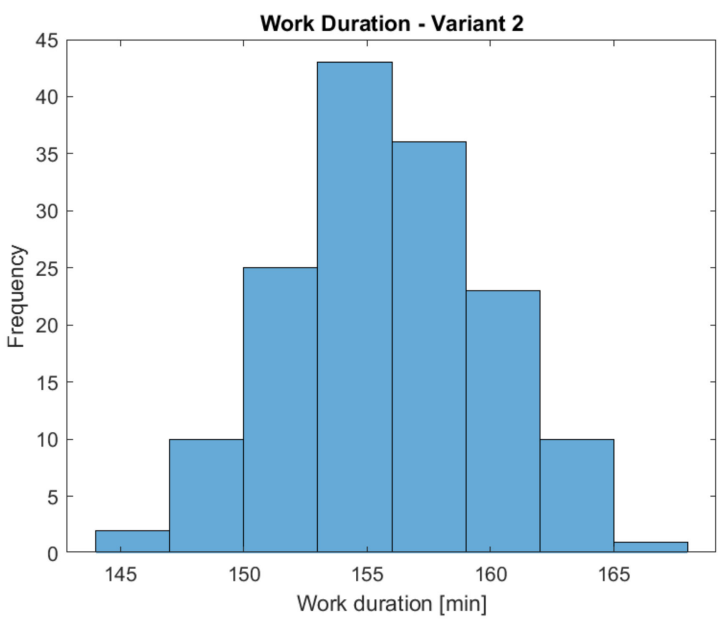

(b)

Figure 8. Duration of the solved aerial works in the construction of the Bachledova dolina-Malá Pol'ana cableway (Slovakia) according to Variant 1 (a) and Variant 2 (b) - -histograms.

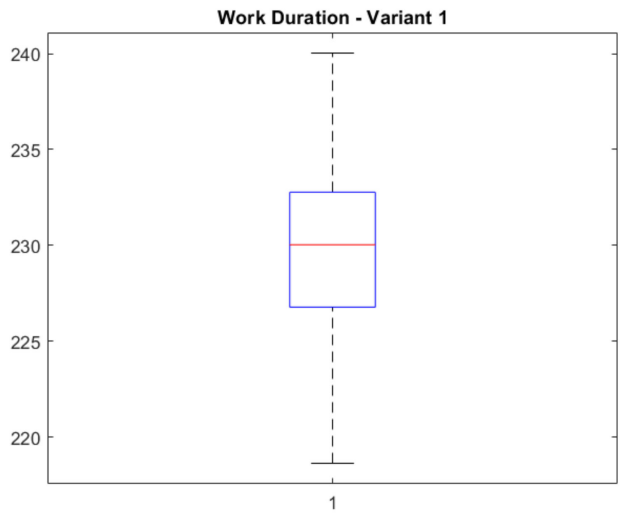

(a)

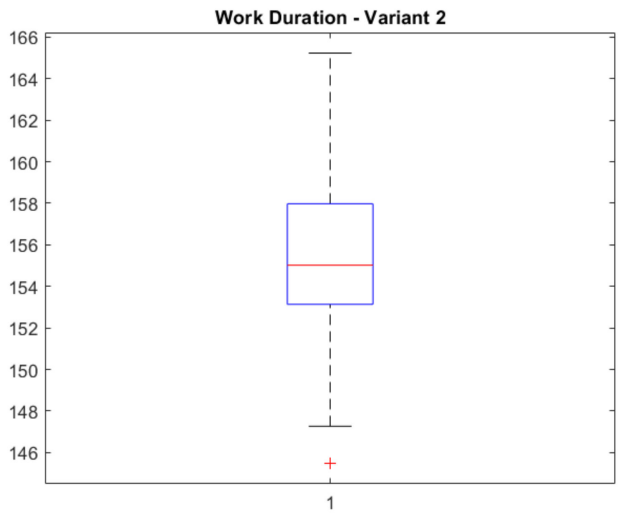

(b)

Figure 9. Duration of the resolved aerial work on the construction of the Bachledova dolina-Malá Pol'ana cableway (Slovakia) according to Variant 1 (a) and Variant 2 (b) - box plots.

The presented analysis shows that the determined capacity of a helicopter by its manufacturer may not be easy to achieve in practice, so it is necessary to respect the influence of randomly changing construction conditions and, at the same time, the specific conditions of the helicopter's work during the preparation of the construction processes implemented by the helicopter. The complexity of such a system can therefore be appropriately modeled using the above simulation models.

\section{Discussion}

This work can be considered a loose continuation of the work [15], which dealt with the influence of weather conditions on the construction of high-rise buildings. The construction work carried out by helicopters can, in a sense and after some simplification, be considered as an analogy for carrying out construction work on such type of buildings. In contrast to the mentioned work, in which the weather forecast at the construction site was obtained using a weather generator, we used the numerical weather prediction model, which provided a vertical weather profile automatically without the need to calculate it. We believe that, in the case of work performed by helicopters, this method is more suitable, 
especially in connection with the high sensitivity of a helicopter to changes in weather conditions that affect its basic technological properties. Another advantage of this method is the ability to predict weather conditions that have not occurred in the past, which is especially important in the context of climate change [15,22].

The basic idea of simulation modeling in the preparation of buildings is to replicate as closely as possible the situation at the intended real construction site. The importance of this step is emphasized by Balakchina and Shalenny [8], who stated that the number of flight hours and the price per flight hour of a helicopter are often the main factors influencing the cost of the process; therefore, it is appropriate to verify the proposed process by simulation and choose the most advantageous among the different variants. Thus, when setting up the simulation model for helicopter work, other specific issues that must be addressed for the use of a helicopter at a construction site have emerged and are the subject of discussion:

On what basis does a helicopter pilot make decisions in relation to the overall organization of aerial work?

How and at what intervals is the refueling of a helicopter fuel tank handled during the execution of this work?

How do the slenderness of the load and its area affect the flight of a helicopter, especially with respect to wind loads or rotation of the load in the helicopter's undercarriage?

Which aspects determine the deployment of a particular type of helicopter at a particular construction site?

Which activities before, during, and after aerial work can be considered negligible for simulation purposes, and which cannot be considered so?

With the intention of capturing the course of helicopter work as authentically as possible, and thus increasing the value of the simulation model, we also consulted these points in reference to aviation practice. However, despite the efforts made, it is possible that the simulation model may need to be corrected slightly (refined) for its eventual wider use. Within the framework of the performed case study, but as well as during the verification of the model, we focused on the solution of the construction of cableway supports, i.e., on the assembly process. This focus resulted, on the one hand, from the available possibilities of capturing actual projects within a permissible timeframe and, on the other hand, from the availability of the necessary documentation that was available to the authors of the article due to their professional backgrounds. The presented issue is quite extensive; therefore, these examples are seen more as clues that point the way to the possible further use of both simulation models and numerical weather prediction at the present level in the preparation of any type of building.

The simulation model can be further extended and refined in the future. It seems to be an interesting idea to consider three important points during the helicopter flight instead of one, taking into account the expected weather conditions. These points are the helicopter's home airfield (often located hundreds of kilometers from the construction site, sometimes in a neighboring country), the helicopter's take-off area in the field, and the construction site itself. Using current numerical weather prediction capabilities, attention can also be focused on the solution of the entire helicopter flight path and altitude profile, both during the overflight to the construction site and during the actual construction. This brings the simulation even closer to objective reality, where the boundary conditions change naturally over time [24].

The design and implementation of the simulation model was performed in the sense of the greatest possible future flexibility, so the model can be used in any construction process, including important and technologically more complicated concrete processes. Simulation of the concreting process would be carried out in an analogous way to the assembly process, in principle, with only one difference: the input weights of the loads must be given to take into account the weight of the concrete basket together with the weight of the fresh concrete itself in the basket. In this case, it is advisable to add to the simulation model the continuous monitoring of the duration of the stay of the truck mixer with fresh concrete at the site and the subsequent alert in case the total processing time of 
the fresh concrete at the site exceeds its permissible workability time. In the case of the assembly process, it is possible to address the priority of the transported loads so that the assembly of horizontal load-bearing structures does not precede the assembly of vertical load-bearing structures. In the simulation model, this situation can occur, e.g., by omitting flight with a vertical structure due to adverse weather.

The issue of the weight of the fuel in the tanks, the amount of which in practice is unique for each building project, also proves to be extremely interesting. Refining the amount of fuel and its effect on a helicopter's payload capacity at a particular site may represent a noteworthy direction for future research, which involves not only the economic plane, but also the environmental one. However, due to its nature (the flight part), it must be carried out in close cooperation with the airline operator, which alone has the necessary know-how. In this context, we state that, in the field of aerial work with helicopters in construction, there is a lack of professional literature, and cooperation with companies is therefore the only real way to obtain important information.

In addition to the Mi-8 helicopter type, the database of input data can be supplemented with other frequently used helicopter types (especially the Mi-17 type under the conditions of the Central Europe region), and the simulation solution can also consider various random phenomena occurring in practice and a suitable way of taking them into account-particularly the randomness of helicopter malfunctions, the randomness of traffic complications, and other phenomena that could have an impact on the course of the solved process. Depending on their degree of significance, they can be solved using appropriate coefficients (deterministically) or stochastically. The input data can be checked qualitatively using appropriate statistical methods, e.g., normality tests. In terms of outputs, it is possible to extend the statistical indicators or graphs offered.

The outputs of the proposed simulation model can be automatically implemented in the future in the processes of construction-technological preparation. This means that the basic technological documents (construction schedule, financial plan, etc.), nowadays usually processed on a computer using specialized software, can, as a result of their optimization on the basis of the simulation model outputs, more accurately replicate the reality of construction, especially in the area of defining the necessary time and financial reserves and the resulting technological impacts. This approach would also allow these documents to be updated in real time according to the work actually being carried out, which will significantly increase their level of practical usability. At the same time, this also fulfils one of the main requirements for any type of planning, namely, the necessity of keeping plans up to date, which is often problematic.

Thus, the output can be an operational (short-term) time plan, which brings benefits not only to the general contractors and subcontractors of aerial works, but also to the investors and the public. Construction contractors will appreciate the knowledge of the exact situation, especially in the coordination of construction processes, where the model will help project managers. Airline operators will obtain an automated system that will save time compared to manual processing and will allow the ability to verify alternative scenarios in the event of operational delays due to adverse weather, which, in practice, occurs very often. Balakchina and Shalenny [8] noted that the achievement of efficiency in aerial work using a helicopter directly depends on the ability of the construction contractor to take into account the characteristics of the helicopter and the overall quality level of construction technology preparation, with regard to the technological and organizational regularities of such work. We share this view. The optimization of schedules and financial plans and the determination of necessary reserves with the application of simulation outputs could, in practice, contribute to the elimination of helicopter downtime in the field, e.g., due to adverse weather or the incorrect sequence of works, to the minimization of the required number of flights to the construction site and various loss times, or to the determination of the optimal amount of aviation fuel to be transported to the construction site by tanker truck, and thus to maximize the efficiency of this method of construction implementation. 
Thanks to the advanced preparation of the construction work, the investors, as well as the public, will also appreciate the accompanying environmental aspect. This aspect is of particular importance in the case of helicopter work, both in mountainous areas (minimizing the negative impact on protected natural areas) and in built-up areas (minimizing the unavoidable accompanying noise characteristic of helicopter operations). Thanks to this approach, investors and contractors can also ultimately prove that they apply the philosophy of corporate social responsibility (CSR). At present, this means an indisputable benefit on the market, especially in the interest of sustainable development. It also helps to build a positive image of the organization.

At the same time, the economic efficiency of the aerial work achieved should allow this environmentally friendly technology to be used wherever it represents a technically ideal solution and not substituted by ground-based alternatives with a higher risk of impact on the surrounding environment solely due to price ranges. We are of the opinion that a similar approach, using simulations, could find application again in a broader context beyond aerial work, using helicopters in a time of gradual digitalization of the construction industry in the spirit of Industry 4.0 ideas. In connection with the used concept of the simulation model, based on various types of numerical weather forecast models, we consider it appropriate to mention that, even in the case of a fully automatic decision-making system designed in this way, in practical terms, we recommend consulting a professional meteorological service in the 48 or $24 \mathrm{~h}$ preceding actual implementation of a work plan. Under the conditions of Slovakia, it is therefore advisable to contact the Slovak Hydrometeorological Institute, which deals with current weather $24 \mathrm{~h}$ a day.

Lee et al. [24] emphasized the benefits of teaching simulation at universities because simulation allows students to model problems from everyday life, experiment with different scenarios and variants, and observe changes. We share this view; we think that it is the variety of solutions that simulation provides in principle that can lead students to an analytical way of thinking, and thus an understanding of how to solve real-world problems in engineering practice, which normally requires making a choice from different options based on established criteria.

On the other hand, simulation tools have relatively high demands on computing power, which may not be easy to provide, especially from a financial point of view. Another problem associated with teaching can be the considerable amount of time needed to build the simulation model and logistical and financial complexity in obtaining input data. Knowledge of programming was also required to build the simulation model in our work. However, from a practical point of view, it is possible (both in teaching and in practice) to build the model using software that is based on prepared building blocks. In this way, the compilation of the model is accelerated, and the focus of the work can be devoted to experimenting with it, and thus finding the optimal variant of the process, which students will appreciate, especially in engineering practice.

\section{Conclusions}

The aim of the present paper was to highlight the fact that the fundamental requirement of sustainability can also be found and achieved in the context of technologies with an extremely specific character, such as aerial work using helicopters, in the whole environmental and economic context. Especially in the environment of protected landscapes and national parks, all sites are sensitive to human intervention, and therefore, the use of helicopters in construction is an indispensable aid for these areas. At the same time, they are proving to be a cheaper and shorter option for the implementation of construction works compared to conventional ground technology. The preparation of aerial work using helicopters, especially given their high degree of susceptibility to weather conditions, is very demanding and requires the use of more sophisticated tools to achieve optimal results consistent with the long-term sustainability paradigm. One possibility, also thanks to the considerable development in information technology, is simulation modeling. 
Based on the knowledge gained by imaging real processes, as well as on relevant information from construction practice, a simulation model of aerial work using helicopters was compiled, and its functionality was verified using specific examples that fully confirmed the suitability of using simulation in this situation. A key characteristic of the proposed simulation model is resolution of the influence of weather conditions on construction work, the algorithm for which was designed using various commercially available numerical weather forecast models, such as the IFS, ALADIN, and A-LAEF models.

The presented research expands the knowledge in the field of preparation for construction work employing helicopters under demanding construction conditions, and it contributes to the digitization of construction preparation, which is an essential part of Industry 4.0. The simulation model can be beneficial for construction contractors and air operators in aviation practice, simplifying the process of preparing constructions carried out by helicopters. Its outputs can also be appreciated by investors of such constructions; given the environment in which aerial works with helicopters usually take place, it can ultimately provide them prestige in the eyes of the public as a company that uses modern technologies that contribute to the protection of the environment through sustainable forms of business. At the same time, the interdisciplinary nature of the work contributes to the expansion of knowledge beyond construction, especially in the field of numerical weather forecasting (knowledge from the practical application of the SHMÚ models and methodology of working with models) and in industrial logistics (knowledge from the application of simulation modeling in construction production).

Author Contributions: Conceptualization, A.B. and Z.H.; data curation, A.B. and M.N.; formal analysis, A.B., Z.H. and M.N.; funding acquisition, A.B. and Z.H.; investigation, A.B. and M.N.; methodology, A.B., Z.H. and M.N.; project administration, A.B. and B.C.; resources, A.B., Z.H., M.N. and B.C.; software, A.B.; supervision, A.B.; validation, A.B. and Z.H.; visualization, A.B. and M.N.; Writing—original draft, A.B., Z.H. and M.N.; writing—review and editing, Z.H. and B.C. All authors have read and agreed to the published version of the manuscript.

Funding: This paper was created as research work for the project VEGA No. 1/0511/19.

Institutional Review Board Statement: Not applicable.

Informed Consent Statement: Not applicable.

Data Availability Statement: Not applicable.

Acknowledgments: The authors express their gratitude for the memories and photographic archives shared by the collective of former employees of the former Transporta, n.p. Chrudim (1945-1999), which, in the former Czechoslovakia, contributed significantly to the introduction of aerial work with helicopters in the construction industry in practice.

Conflicts of Interest: The authors declare no conflict of interest.

\section{References}

1. Svoboda, V. Vrtulníky [Helicopters]; Naše Vojsko: Prague, Czech Republic, 1979. (In Czech)

2. Jindra, F. Stavebně Montážní Práce s Využitím Vrtulníkũ v ČSSR [Construction Work Using Helicopters in ČSSR]; NADAS: Prague, Czech Republic, 1965. (In Czech)

3. Cowen, M.; Muranaka, G. Construction Challenges in Paradise Hawaiian Electric Company-138 kV System Rebuild. In Electrical Transmission and Substation Structures 2018: Dedicated to Strengthening our Critical Infrastructure, Proceedings of the 2018 Electrical Transmission and Substation Structures Conference, Atlanta, GA, USA, 4-8 November 2018; American Society of Civil Engineers: Reston, VA, USA, 2018; pp. 36-46. [CrossRef]

4. Paharik, M.J. The Pyramids of Pensacola: Gulf Power Company's Crist to Holley 115kV Transmission Line Upgrade. In Electrical Transmission Line and Substation Structures: Structural Reliability in a Changing World, Proceedings of the 2006 Electrical Transmission Conference, Birmingham, AL, USA, 15-19 October 2006; American Society of Civil Engineers: Reston, VA, USA, 2006 ; pp. $374-381$. [CrossRef]

5. Murley, S.C.; Strom, C.M.; Herron, J.W. Use of Alternate Foundations to Overcome Design and Construction Challenges in Mississippi Backwater. In Geo-Congress 2020: Foundations, Soil Improvement, and Erosion; American Society of Civil Engineers: Reston, VA, USA, 2020; pp. 256-270. [CrossRef] 
6. Davidow, S.A.; Carr, D.G. Micropile Design and Construction in a Limited Access Wetland Habitat. In Electrical Transmission and Substation Structures 2015: Technical Challenges and Innovative Solutions in Grid Modernization, Proceedings of the 2015 Electrical Transmission and Substation Structures Conference, Branson, MO, USA, 27 September-1 October 2015; American Society of Civil Engineers: Reston, VA, USA, 2015; pp. 35-45. [CrossRef]

7. Fiske, A.; Dell, H. Jack Rabbit-Big Sky 161 kV National Forest Canyon Construction. In Electrical Transmission and Substation Structures 2015: Technical Challenges and Innovative Solutions in Grid Modernization, Proceedings of the 2015 Electrical Transmission and Substation Structures Conference, Branson, MO, USA, 27 September-1 October 2015; American Society of Civil Engineers: Reston, VA, USA, 2015; pp. 23-34. [CrossRef]

8. Balakchina, O.; Shalenny, V. Design organization and construction implementation of the installation and reconstruction technology using helicopters. IOP Conf. Ser. Mater. Sci. Eng. 2020, 913, 042039. [CrossRef]

9. Bisták, A.; Hulínová, Z.; Neštiak, M. Simulation Modelling of Aerial Works and Its Role in the Preparation of Construction. Slovak J. Civ. Eng. 2021, 29, 20-26. [CrossRef]

10. Veselý, J. Přeprava betonu při stavbě lanovky na Sněžku [Transport of concrete during construction of the cableway on Sněžka]. Beton Technol. Konstr. Sanace 2013, 13, 26-29. (In Czech)

11. Wyman, G.E. Transmission line construction in sub-arctic Alaska case study: “Golden Valley Electric Association's $230 \mathrm{kV}$ Northern Intertie". In Electrical Transmission and Substation Structures 2009: Technology for the Next Generation, Proceedings of the 2009 Electrical Transmission and Substation Structures Conference, Fort Worth, TX, USA, 8-12 November 2009; American Society of Civil Engineers: Reston, VA, USA, 2009; pp. 329-341. [CrossRef]

12. Char, C.Y.; Lembke, J.L. The Hawaiian Electric Company Koolau-Pukele 138kV line structures \#2 and \#9 replacement project. In Proceedings of the Electrical Transmission in a New Age, Omaha, NE, USA, 9-12 September 2002; pp. 188-199.

13. Mehrabi, A.B. Luling bridge stay cable replacement. In Don't Mess with Structural Engineers: Expanding Our Role, Proceedings of the 2009 Structures Congress, Austin, TX, USA, 30 April-2 May 2009; American Society of Civil Engineers: Reston, VA, USA, 2009; pp. 498-507. [CrossRef]

14. Lee, H.-S.; Shin, J.-W.; Park, M.; Ryu, H.-G. Probabilistic duration estimation model for high-rise structural work. J. Constr. Eng. Manag. 2009, 135, 1289-1298. [CrossRef]

15. Jung, M.; Park, M.; Lee, H.-S.; Kim, H. Weather-delay simulation model based on vertical weather profile for high-rise building construction. J. Constr. Eng. Manag. 2016, 142, 04016007. [CrossRef]

16. AbouRizk, S.M.; Wales, R.J. Combined discrete-event/continuous simulation for project planning. J. Constr. Eng. Manag. 1997, 123, 11-20. [CrossRef]

17. Muhabie, Y.T.; Rigo, P.; Cepeda, M.; D'Agosto, M.D.A.; Caprace, J.-D. A discrete-event simulation approach to evaluate the effect of stochastic parameters on offshore wind farms assembly strategies. Ocean. Eng. 2018, 149, 279-290. [CrossRef]

18. Racsko, P.; Szeidl, L.; Semenov, M. A serial approach to local stochastic weather models. Ecol. Model. 1991, 57, 27-41. [CrossRef]

19. Caraway, N.M.; McCreight, J.L.; Rajagopalan, B. Multisite stochastic weather generation using cluster analysis and k-nearest neighbor time series resampling. J. Hydrol. 2014, 508, 197-213. [CrossRef]

20. Shahin, A.; AbouRizk, S.M.; Mohamed, Y. Modeling Weather-Sensitive Construction Activity Using Simulation. J. Constr. Eng. Manag. 2011, 137, 238-246. [CrossRef]

21. Kim, S.H.; Augenbroe, G. Using the National Digital Forecast Database for model-based building controls. Autom. Constr. 2012, 27, 170-182. [CrossRef]

22. Schuldt, S.J.; Nicholson, M.R.; Adams, Y.A.; Delorit, J.D. Weather-Related Construction Delays in a Changing Climate: A Systematic State-of-the-Art Review. Sustainability 2021, 13, 2861. [CrossRef]

23. Mohamed, E.; Jafari, P.; Chehouri, A.; AbouRizk, S. Simulation-Based Approach for Lookahead Scheduling of Onshore Wind Projects Subject to Weather Risk. Sustainability 2021, 13, 10060. [CrossRef]

24. Lee, S.; Behzadan, A.; Kandil, A.; Mohamed, Y. Grand challenges in simulation for the architecture, engineering, construction, and facility management industries. In Computing in Civil Engineering, Proceedings of the 2013 ASCE International Workshop on Computing in Civil Engineering, Los Angeles, CA, USA, 23-25 June 2013; American Society of Civil Engineers: Reston, VA, USA, 2013; pp. 773-785. [CrossRef]

25. Messingerová, V. Technológia Vzdušnej Dopravy Dreva v Lesníctve [Technology of Air Transport of Wood in Forestry]; Technical University in Zvolen: Zvolen, Slovakia, 2005. (In Slovak)

26. Kadlec, M. Výkonnost-Vrtulníky (034 00). Učební Texty dle Předpisu JAR-FCL 2 [Flight Performance-Helicopters (034 00)]; Akademické Nakladatelství CERM: Brno, Czech Republic, 2011. (In Czech)

27. Schoř, J.; Šustek, P. Hmotnost a Vyvážení-Vrtulniky (031 00). Učební Texty dle Předpisu JAR-FCL 2 [Weight and Balance-Helicopters (031 00)]; Akademické Nakladatelství CERM: Brno, Czech Republic, 2008. (In Czech)

28. Dosoudil, E.; Velička, K.; Němec, B.; Drobílek, O. Létající Jeřáby. Sborník Přednášek [Flying Cranes. Conference Proceedings]; Transporta, n.p. Chrudim and Dom techniky ČVTS: Pardubice, Czech Republic, 1971. (In Czech)

29. Bartoš, R. et al. Vrtulníky Při Stavebně-Montážních Pracech a Transportu Materiálu. Sborník Přednášek [Construction Works Carried Out by Helicopters. Conference Proceedings]; Dom Techniky ČVTS Pardubice: Pardubice, Czech Republic, 1973. (In Czech)

30. TOP500. The List. Available online: https://www.top500.org/lists/top500/list/2021/06/ (accessed on 21 August 2021). 
31. Termonia, P.; Fischer, C.; Bazile, E.; Bouyssel, F.; Brožková, R.; Bénard, P.; Bochenek, B.; Degrauwe, D.; Derková, M.; El Khatib, R.; et al. The ALADIN system and its canonical model configurations AROME CY41T1 and ALARO CY40T1. Geosci. Model. Dev. 2018, 11, 257-281. [CrossRef]

32. Derková, M.; Vivoda, J.; Belluš, M.; Španiel, O.; Dian, M.; Neštiak, M.; Zehnal, R. Recent improvements in the ALADIN/SHMU operational system. Meteorol. J. 2017, 20, 45-52.

33. Belluš, M.; Weidle, F.; Wittmann, C.; Wang, Y.; Taşku, S.; Tudor, M. Aire Limitée Adaptation dynamique Développement InterNational-Limited Area Ensemble Forecasting (ALADIN-LAEF). Adv. Sci. Res. Contrib. Appl. Meteorol. Climatol. 2019, 16, 63-68. [CrossRef]

34. Wang, Y.; Belluš, M.; Ehrlich, A.; Mile, M.; Pristov, N.; Smolíková, P.; Španiel, O.; Trojáková, A.; Brožková, R.; Cedilnik, J.; et al. 27 years of regional cooperation for limited area modelling in central Europe. Bull. Amer. Meteorol. Soc. 2018, 99, 1415-1432. [CrossRef]

35. Wang, Y.; Belluš, M.; Wittmann, C.; Steinheimer, M.; Weidle, F.; Kann, A.; Ivatek-Šahdan, S.; Tian, W.; Ma, X.; Tascu, S.; et al. The Central European limited-area ensemble forecasting system: ALADIN-LAEF. Q. J. R. Meteorol. Soc. 2011, 137, 483-502. [CrossRef]

36. AbouRizk, S.; Halpin, D.; Mohamed, Y.; Hermann, U. Research in Modeling and Simulation for Improving Construction Engineering Operations. J. Constr. Eng. Manag. 2011, 137, 843-852. [CrossRef]

37. Hulínová, Z. Analýza Stavebných Procesov z Hl'adiska Ich Modelovania [Analysis of Construction Processes in Terms of Modelling]; Nakladatel'stvo STU: Bratislava, Slovakia, 2011. (In Slovak)

38. Object Management Group. Available online: https://www.omg.org/spec/BPMN/2.0/ (accessed on 17 September 2021).

39. Mahmoodzadeh, A.; Zare, S. Probabilistic prediction of expected ground condition and construction time and costs in road tunnels. J. Rock Mech. Geotech. Eng. 2016, 8, 734-745. [CrossRef]

40. Liu, D.; Xuan, P.; Li, S.; Huang, P. Schedule Risk Analysis for TBM Tunneling Based on Adaptive CYCLONE Simulation in a Geologic Uncertainty-Aware Context. J. Comput. Civil. Eng. 2015, 29, 04014103. [CrossRef]

41. Alsudairi, A.A. Simulation as a Tool for Assessing the Economical Aspects of Construction Processes. Procedia Eng. 2015, 118, 1086-1095. [CrossRef]

42. Kim, T.; Kim, Y.-W.; Cho, H. Dynamic production scheduling model under due date uncertainty in precast concrete construction. J. Clean Prod. 2020, 257, 120527. [CrossRef] 